\title{
The Resultant Force of a Multimedia Mobile Application
}

\author{
Dinu MIHAIL-VĂDUVA \\ Bucharest University of Economic Studies \\ dinu.mihailvaduva@stud.ase.ro
}

The impact of a multimedia mobile application concerning self-efficacy about personal evaluation on the academic performance is studied with a theoretical model that emulates the interface with a learning and evaluation educational evolution, delivered one after another, with no time separation between them. Our theoretical model offers an introduction of an indicator metric, symbolized in this paper work with acronym PE, as a tool to define a bridge between the time allocated for each of the three stages of an educational process composed by: teaching, practice and evaluation. A dedicated multimedia mobile application was created to be implemented across a sample population of students using a unique theme and four different versions that simulates a decreasing concentration of multimedia contents. In order to start a parallel approach to our indicator metric, PE, we propose utilization of an interpretation supporting vector analysis starting from our assumption that both formal and informal evaluation could be assimilated together with a scalar vector outcome as a resultant force of final evaluation regarding academic performance. This last objective will be considered as a supplementary evidence on behalf of our indicator metric PE. We emphasized two areas in our laboratory experiment, with different patterns regarding educational energy that flows from instructor or teacher reciprocally toward to the learner, with the status of exothermic and endothermic educational activities. Our last educational energy classification will be considered as a teacher person point of view. In this paper the master objective was to observe the moment when an individual learner uses a multimedia mobile application and to explain with multiple regression analysis outcomes observed. We search possible connections between independent variables represented by time coverage of different educational stages and a dependent variable represented by the indicator metric PE and, furthermore, by the resultant of force resulted from formal and informal evaluation.

Keywords: mobile applications, mobile learning, Android, impact on academic performance DOI: $10.24818 /$ issn14531305/24.3.2020.03

\section{Introduction}

Every collectivity of learners contains persons that willingly accept procedures to achieve more knowledge. When a mobile device is involved into an educational process with multimedia mobile applications we should consider a complex system where different forces action upon every individual named as a learner. Those forces could convey abnormal behavior as we noticed from a study written by Mendoza [1] and Gokçearslan [2]. They described a social phenomenon characterized by a real fear involving a possible situation when their personal mobile device is not working or missing. Other peculiar situation, regarding incorrect utilization of a mobile device, is represented by an uncanny desire to elude mandatory tasks derived by minimal educational requirements that assume to be involved with maximum attention toward teacher during a normal classroom activity. Different statistical methods like well-known questionnaire or survey were used to anatomize quality metrics regarding both hardware mobile devices and software multimedia mobile application. These methods investigate visual and verbal cognitive abilities that could be a basis toward a better educational performance. It is a truism that formal evaluation is very important for every teachable person that attends a mandatory cycle of education because, regardless of scoring method used in different countries, a stigmatizing resultant force occurs after a final evaluation is completed. This educational force could be seen like a 
resultant of a concurrent dual form between formal force and informal force evaluation or, in another way of saying, between what a teachable person gets versus what he envisions realizing. The resultant force in a multimedia environment imposed by mobile apps could be the determinant factor for not well balanced behavior observed by researchers like Bakon [3] and Shahibi [4] who noticed relevance of nomophobia or cyberloafing. A large activity of reviewing scientific literature was started to search the evidence of correlation between academic performance, time and quality metrics attached to the mobile applications covered with multimedia effects interpreting them in our laboratory experiments with the help of a vectorial perspective. This paper is composed as we describe in the following rows.

The first chapter is an introduction to our target and gives an explanation toward the objective of this paper. The second chapter is a review of scientific articles that emphasizes correlations between similar scientific research concerning our target, mostly those regarding academic performance and the impact of mobile applications. The third section presents the methodology that we are proposed for our objective. The next section introduces a laboratory experiment study that involves a mobile application with multimedia support, in four different versions, to calculate the quality metric defined by selfevaluation of academic performance and the resultant force of academic evaluation as a measurement of the impact of mobile application toward the community of teachable learners. The paper ends with wellbalanced discussions, conclusions and details about similar objectives that we hope to study in the future.

\section{Literature review}

An independent variable like time spent with handling mobile multimedia applications is a key component of different statistical studies that aim to discover relevant correlations with educational performance, in various forms, dictated by regional rules. The teacher is orientated toward a global performance of his educable collectivity and a teachable person who attends this community is willing to obtain a personal educational score uncorrelated with global performance metrics. Because a mobile device is wide spread among educable collectivity a desire to conceive experiments with many observations conducted by subjective methods, like questionnaire, to achieve scientific data, is well justified. This is case of the scientific paper work written by Salvation [5] where large target population with undergraduate college people were asked to disclose the amount of time affected by different activities using mobile devices. The conclusion of this research study is that the time spent with multimedia learning mobile tools is direct proportional with general school performance regarding tests and assignments. Students' tendency to excessive use of mobile devices was studied by Amez [6] that concluded a negative force impact toward learning scoring final results. Overusing network with apps or sites was a primary target to researcher Khan [7] who investigates different activities across a group of students. He revealed activities like transmitting messages, entertainment or informal conversations known as chatting with friends. His findings, based on multiple regression analysis, revealed that students' results suffered a negative force impact from above mentioned activities. The same results were obtained by Ahmed [8] and Foen [9] who builds useful procedures for stakeholders involved toward any decision regarding formal or informal educational process. The researcher Winskel [10] observed similar activities for entertainment, sending or receiving messages or informal conversations when realized experiments with large population of students geographically separated which is a point to the conclusion that is a widespread characteristic. New mobile device habits besides the older method of reading books were studied by researcher Sumathi [11] who studied a correlation between browsing frequencies toward gathering new knowledge from the Internet and the academic performance and his conclusion was that is no evidence of 
interdependence among variables studied. A conclusion regarded circumstances in which a better control of using multimedia mobile applications is desirable was pointed by the researcher Giunchiglia [12] who studied the force of a mobile social usage and the real implications concerning academic performance. He found a negative statistical correlation and by consequence a negative force impact toward general academic performance. If a trend of 5-7 hours consumed to communicate using mobile social applications will be maintained then a negative force impact will be generated toward general academic performance according with the study conducted by the researcher Kibona [13]. Overusing social mobile applications could be the determinant force toward addiction in front of a mobile device identified with the term of technostress as we noticed from a study written by the researcher Shahibi [4]. This determinant force explained a need of touch as a new form of irregular behavior observed in large educational community. This researcher also concluded that a negative force impact will be observed against academic performance if technostress occurs. Another side of the impact between mobile applications and users is related with the financial implications due to all actions needed to be completed to keep up to date a lot of software and hardware resources required by any process of education. This aspect was studied by the researcher Chukwuere [14] who emphasized a positive and negative force correlated with the general academic performance. Increasing addiction regarding a smartphone usage will be generated in a direct proportional way between the total time consumed with cyberloafing activities against abilities like self-efficacy or self-regulation according with the study written by the researcher Gokçearslan [2]. Using the hypothesis between self-efficacy and general academic performance a researcher Sunyoung [15] found a positive force impact between variables involved in his study. Working in groups under different school projects a researcher Jesse [16] concluded that the most of the students are not fully acquaintance with the total possibilities of their own mobile devices which is a barrier set upright between normal mobile connections during classroom activities. A method to build an efficient survey study using questionnaires regarding the effects of multimedia mobile applications usage was created by the researcher Alfawareh [17] and he noticed that creating artificial relationship between coworkers or checking habits influenced with a negative force basic performance of academic personnel and a feeling of hesitancy is rising all the time. When a social media application with critical learning objectives is implemented across mobile devices a positive force impact with be generated toward academic performance of teachable persons. This is a conclusion emerged from a study written by the researcher Boahene [18] who said that his findings should positively influence the stakeholders to create a better policy on how to use in an efficient way mobile application with educational objectives. The role of instructional multimedia components was studied by the researcher Wei [19] who discovered numerical statistical evidence of a force who increase the general rising of academic performance. He used different events concerning film watching activities during classroom educational learning projects. $\mathrm{He}$ concluded that his methods confirmed a positive solution to deliver a better education. The author Bakon [3] is cited when complex implications of using smartphone against general academic performance are needed to be understood in a scientific path of doing proved positive correlation between student abnormal behavior and potential social value of the mobile devices. When we are searching evidence about criteria like entertainment, time wasting and nomophobia a study done by the author Mendoza [1] is important because he emphasized, through laboratory experiments, the conditions needed to be completed by a group of mobile devices scatter across an educable collectivity that could lead to a lack of equilibrium between general attention and final evaluation results. 
He discovered a negative force impact, regarding formal final evaluation about academic performance, for those students that practice cyberloafing during classical teaching session. The author Hossain [20] emphasized the role of variety-seeking options regarding usage of mobile applications when he analyzed effects correlated with the academic performance. He found that the indicator metric of varietyseeking could have a positive impact toward academic performance. The researcher Wang [21] realized a study where he disclosed a better way to understand the difference between abilities like visual versus verbal cognitive in an educational environment. $\mathrm{He}$ completed extensive laboratory experiments and he concluded that visual cognitive abilities confirmed greater values of correlations between variables toward academic performance.

\section{Methodology}

Our experimental objective is to define a path where the concept of the force could be embedded into a new way of interpreting a complex educational phenomenon emerged from the interaction between a teachable person and a multimedia mobile application attached to a mobile device. We propose that both formal evaluation and informal evaluation are envisioned with the classical notion of a vector because they convey an educational magnitude, direction and orientation in time. The value of educational evaluation, regardless of its type and provenance, could be associated with a specific magnitude and, for this reasoning, we might assume, in our laboratory experiment, the existence of a unit of educational measurement. We proposed for a unit of educational measurement the quantity of information achieved during a precise period of time for educational learning. For an educational system where a teachable person interacts with a multimedia mobile application deployed into a mobile device we proposed a schematic representation depicted in figure 1.

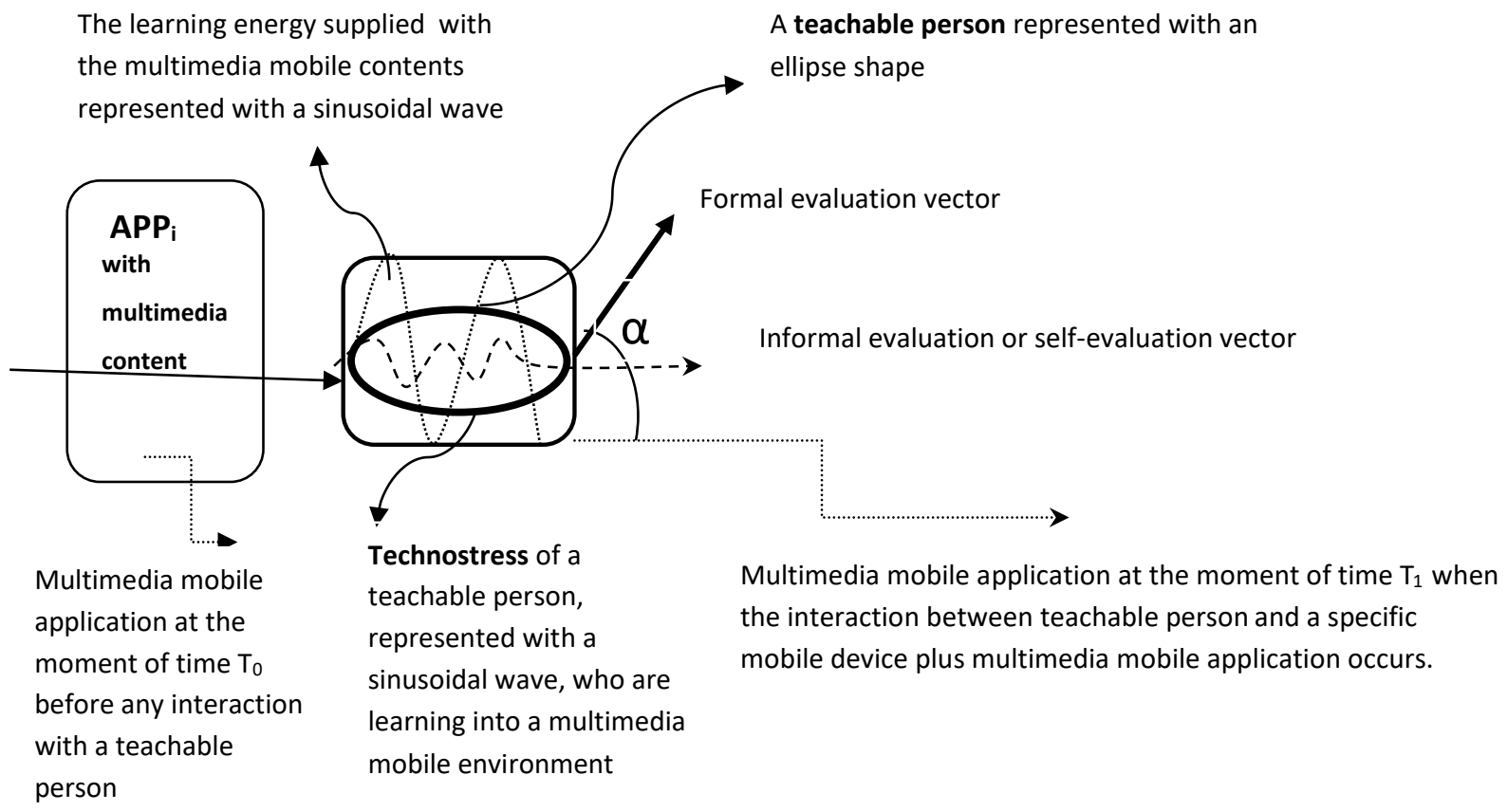

Fig.1.The moment of impact between a teachable person and a multimedia mobile application

In figure 1 we introduced the angle $\alpha$ between formal evaluation vector and self-evaluation vector because the learning energy transferred to the teachable person during learning process is different, in a direct proportional experimental assumption, according with the 
concentration of multimedia components. When the angle $\alpha$ is 90 degree, the formal evaluation vector is orthogonal with the selfevaluation vector, we obtain the situation when the multimedia mobile application has a maximum technostress influence toward a teachable person. The notion of technostress was introduced in scientific literature studied by the author Shahibi [4] and in our experiment emulates the phenomenon of overusing mobile learning application. In this last case the learning energy of a mobile application transferred to a teachable person is at the highest level possible. When the angle $\alpha$ is 0 degree the formal evaluation vector has the same direction and orientation with the self-evaluation vector because the learning energy transferred by the mobile application, toward the teachable person, is similar with the case when the teachable person reads a book or an electronic document like a PDF one. In this last case the learning energy of a mobile application transferred to a teachable person is at the lowest level possible. From figure 1 we noticed that self-evaluation and formal evaluation vectors begin when the multimedia mobile application is finished. The self-evaluation vector is a consequence of subjective perception about the multimedia content that emulates the whole classical method of teaching meaning the presence of a teacher, conversation with an instructor and doing several sessions of remembering new concepts acquired. Our research objective is to establish the answer for the following: Is there any correlation between the resultant educational force uncovered from the dual system composed from two educational forces, represented by formal and informal evaluation, and the time consumed with the learning, remembering and evaluation knowledge acquired? The second research question is the following: What is the selfefficacy concerning personal evaluation when we calculate correlation between the time allocated for learning, remembering and evaluating knowledge and a value of an informal evaluation of academic performance? We propose to calculate the resultant force of evaluation with the formula 1 , according with the law of cosine, keeping into account our premise to assimilate the formal and informal evaluation with a vector basis. The formula 1 is our method to insert, with alpha angle, a different concentration of multimedia layers between formal and informal force evaluation concerning academic performance.

$$
R_{f e}=\frac{1}{2} \times \sqrt{\left(F_{e}^{2}+I_{e}^{2}+2 \times F_{e} \times I_{e} \times \cos \alpha\right)}
$$

Where:

$\mathrm{R}_{\mathrm{fe}}=$ the value of the resultant force of evaluation

$\mathrm{F}_{\mathrm{e}}=$ the value of the formal force evaluation

$\mathrm{I}_{\mathrm{e}}=$ the value of the informal force or selfevaluation

$\propto=$ the angle between vector of the formal and informal force evaluation represented in figure 1 according with the concentration of multimedia content. When $\propto$ is equal with 0 we assume in our experiment, consequently, that the multimedia content is missing and, therefore, we obtain the classical arithmetic average between formal and informal evaluation exposed through formula 2

$$
R_{f e}=\frac{F_{e}+I_{e}}{2}
$$

Our proposal with formula 1 is another method to alleviate the value of the resultant of academic evaluation, instead of doing arithmetic or weighted average, keeping into account that we are considering a theoretically representation with vector support and a flow of teaching energy, with multimedia components, represented by a sinusoidal wave.

Our laboratory experiment started in November 2019 at the Bucharest University of Economic Studies using a population of 
170 students grouped around an activity concerning programming mobile application. After processing results we obtained 116 valid records, using a cloud mobile platform based on a free Moodle website, grouped by the type of multimedia mobile application. The multimedia mobile applications, named with $\mathrm{APP}_{\mathrm{i}}$ in figure 1, where $\mathrm{i}$ is an indicator from one to four, have a decreasing multimedia influence from the first application to the last one. Looking for a response for our own power to be self-efficacy regarding selfevaluation before any other external evaluation or feedback we emulate functionalities of a multimedia varietyseeking situations like other researchers Wang [21], Hossain [20] and Foen [9]. The educational content of multimedia applications was focused around elementary notions about Firebase database as a new curriculum objective for population of students tested in our laboratory experiments. The educational subject chosen was a new one

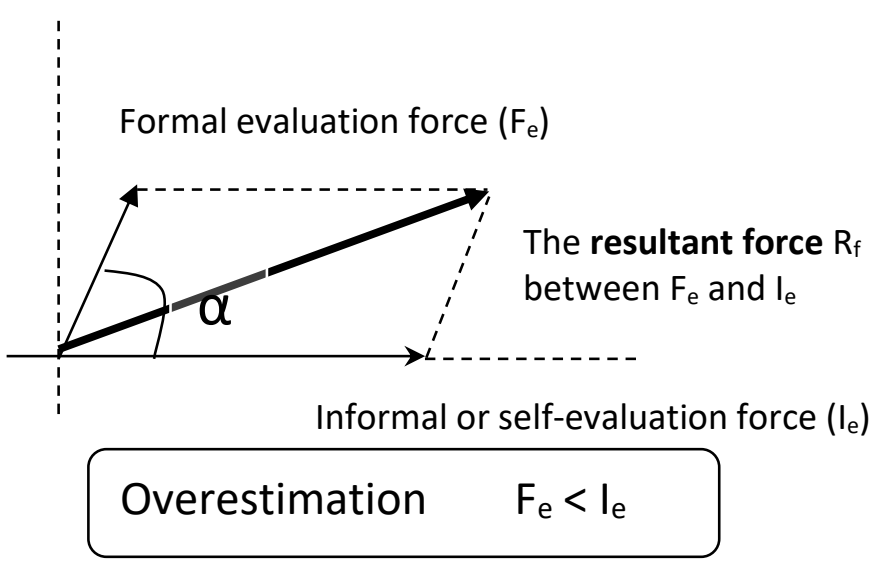

for almost students involved now of running those mobile applications.

The indicator metric represented by the selfevaluation of academic performance, abbreviated with $\mathrm{PE}$, is measuring a personal self-efficacy to be awareness about personal knowledge, at a specific moment of time, when retrieving basic acquisition from memory is meaning a difference from success toward failure in an exam situation. This indicator metric PE is correlated with the whole educable population tested because we are using maximum and minimum functions to border mathematical expressions used for overestimation and underestimation selfevaluation phenomenon but furthermore, in this paper, we are adding a new path centered toward a teachable person without keeping into account the educable community from which he was extracted. The graphical representation of the resultant force $\mathrm{R}_{\mathrm{fe}}$, when overestimation and underestimation phenomenon occur, is shown in figure 2

Formal evaluation force $\left(\mathrm{F}_{\mathrm{e}}\right)$

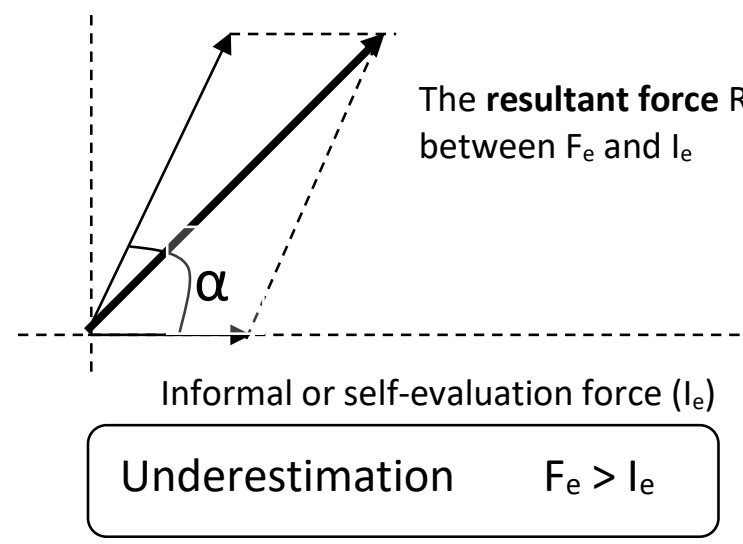

Fig. 2. The graphical representation of the resultant force between $F_{e}$ and $I_{e}$

The resultant vector of an educational force will be a measure on how a teachable person reacts when he is confronted with a complex multimedia mobile application and this reasoning is another way to describe the impact of a multimedia mobile application. The referential system depicted in figure 1 , for every teachable person, is defined by quality characteristics of every mobile hardware used because in our laboratory experiment the rule known as bring your own device, abbreviated with BYOD, and the rule known as bring your own network, abbreviated with BYON, was applied as a premise to our project. Using this motivation, we are considering a supplementary questionnaire and survey, in our mobile multimedia applications, to explain the influence of the multimedia components as a resultant educational force. The multimedia factor was characterized by the presence of the video and sound components emphasized with the embedded virtual instructor participation. The LMS profile chosen to implement these mobile 
applications packages was established to SCORM 1.2. The software format used to run these mobile applications was HTML5 because in this case we obtained a software compatibility with Android, iOS and desktop environment. The general planning experiment was limited by free Moodle website to a number of 50 users with simultaneously access. We proposed a mathematical formula to calculate the content of multimedia components, attached to our multimedia mobile applications, and the classification resulted is shown with numerical values attached in figure 3 .

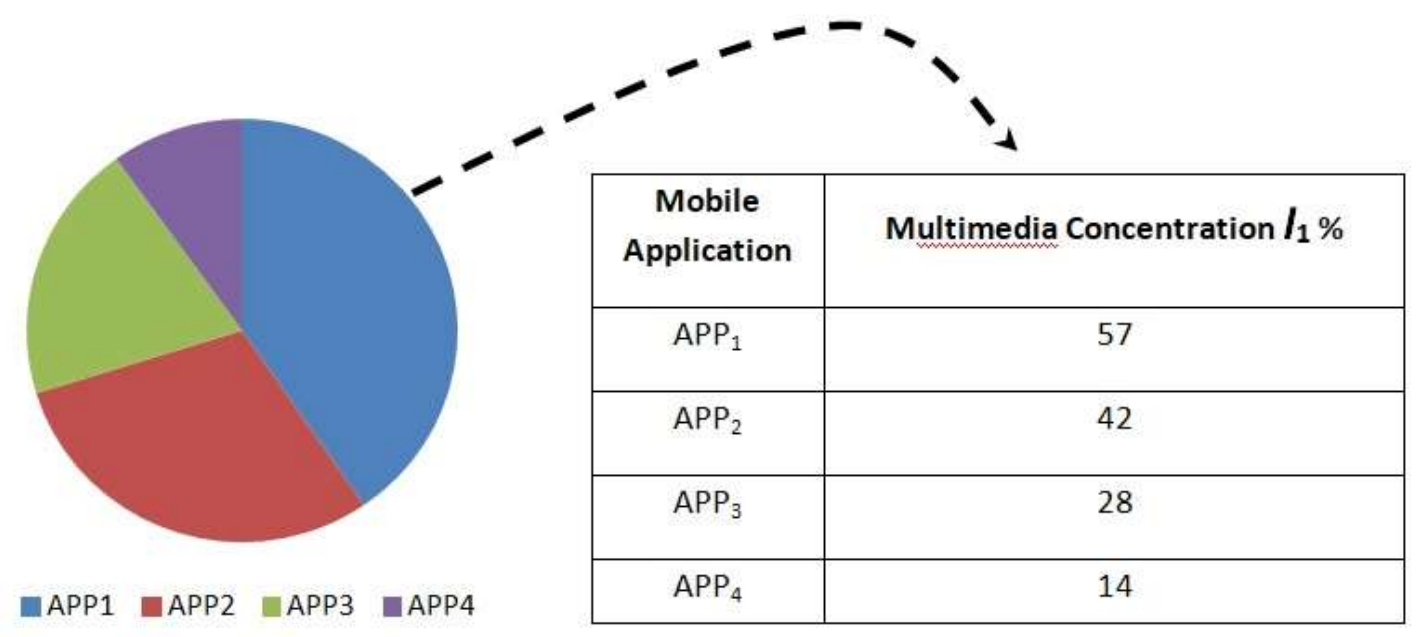

Fig.3 The classification of multimedia mobile applications based on numerical values attached

The multimedia content used in figure 3 consists in the following components shown in table 1

We are using the convention Yes for dynamic multimedia content with effect accordingly, and the convention No for static content similar with the classical electronic documents like PDF ones. The formula 3 is used to calculate the percent of the mobile multimedia concentration exposed in figure 3

$$
I_{1}=\frac{C_{y e s(i)}}{C_{y e s(i)}+C_{n o(i)}}
$$

where:

$\mathrm{C}_{\text {yes(i) }}=$ the total items with Yes value for mobile application $\mathrm{i}$ $\mathrm{C}_{\mathrm{no}(\mathrm{i})}=$ the total items with Yes value for mobile application $\mathrm{i}$

$\mathrm{i}=$ the number of mobile application from 1 to 4

Table 1. The multimedia content policy allocation toward mobile applications

\begin{tabular}{|l|l|l|l|l|}
\hline \multicolumn{1}{|c|}{ Multimedia Component } & APP1 & APP2 & APP3 & APP4 \\
\hline Virtual instructor & $(2)$ & \multicolumn{1}{c|}{$(3)$} & $(4)$ & \multicolumn{1}{c|}{$(5)$} \\
\hline Sound & Yes & No & No & No \\
\hline Callout Text & Yes & Yes & No & No \\
\hline Static presentation & Yes & Yes & Yes & No \\
\hline Simulator for recap & No & No & No & Yes \\
\hline Questionnaire for final evaluation & Yes & Yes & Yes & No \\
\hline Evaluation survey & No & No & No & No \\
\hline
\end{tabular}


The quality of being new for our experimental idea research was demonstrated by the fact that both stages, learning and the evaluation process, took place into an integrated event. The sinusoidal wave of teaching energy transferred from the multimedia mobile application toward the teachable person, depicted in figure 1 , was implemented with a multiple sequence of learning and recap simulation as we presented in figure 4 .

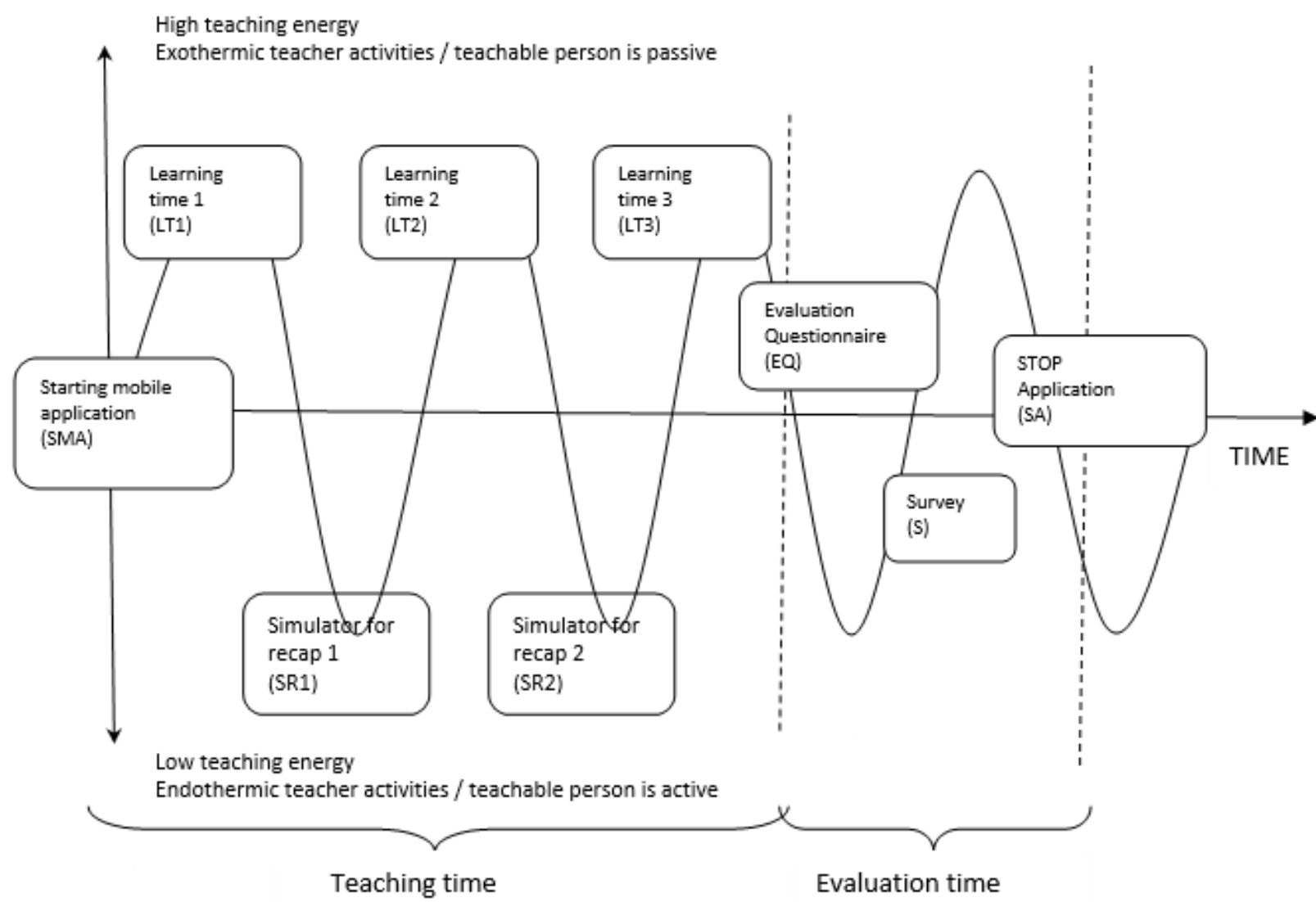

Fig. 4. The flow sequence of teaching energy implemented in multimedia mobile applications

The teaching energy shown in figure 4 emulates the energy of the teacher deployed in a classical method of doing an educational process inside a classroom space. We are assuming in our laboratory experiment that areas of high teaching energy depicted in figure 4 will be allocated to the learning time and the areas of low teaching energy to the recap simulation. We are interested through our research objectives, presented above, to discover how a population of teachable persons receive an impact of a multimedia mobile application explained with the average value of the resultant force emerged as we shown in figure 1 . It is logically to assume in our laboratory experiment that high teaching multimedia energy, exposed in figure 4, reflects an area where the teacher has the fundamental role inside a classroom space, by doing teaching activity releasing energy, and the low teaching multimedia energy reflects an area where teachable persons receive the control of the educational process, by doing homework of recap activities. Furthermore, an activity like evaluation questionnaire implies an increasing energy from the side of the teachable person because at this moment retrieving new knowledge just acquired reclaims a supplementary effort. In opposite to the evaluation questionnaire there is a last action in our experiment where every teachable person sends a feedback through a survey. For this last requirement we assume low energy consumption required from the side of the teachable persons.

The method used in our research to evaluate the individual degree of self-evaluation performance obtained in survey $\mathrm{S}$, displayed 
in figure 4 , is shown by formula 4 for those users that produced an overestimation regarding their self-evaluation of personal academic performance.

$$
P E_{j_{i}}=\frac{\left(\max _{j}\left\{(I E-F E)_{i}\right\}_{j=1}^{N}+1\right)-\left(I E_{j_{i}}-F E_{j_{i}}\right)}{\left(\max _{j}\left\{(I E-F E)_{i}\right\}_{j=1}^{N}+1\right)} \times 100
$$

For those users that produce an academic performance formula 4 will be underestimation regarding their personal translated into formula 5.

$$
P E_{j_{i}}=\frac{\left|\min _{j}\left\{(I E-F E)_{i}\right\}_{j=1}^{N}-1\right|-\left(F E_{j_{i}}-I E_{j_{i}}\right)}{\left|\min _{j}\left\{(I E-F E)_{i}\right\}_{j=1}^{N}-1\right|} \times 100
$$

where:

$\mathrm{j}=$ the indicator of a user with mobile application i from 1 to total number $\mathrm{N}$ of users $\left(\mathrm{APP}_{\mathrm{i}}\right)$

$\mathrm{i}=$ the indicator of a mobile application from 1 to 4

$\mathrm{PE}=$ personal evaluation of individual degree of awareness about self-academic performance.

$\mathrm{FE}=$ formal evaluation based on the internal questionnaire (EQ) true or false answers

$\mathrm{IE}=$ informal evaluation at the end of the internal survey questionnaire $(\mathrm{S})$ meaning a self-evaluation expected by the user before knowing his formal evaluation FE

To correlate the quality characteristic of every mobile application developed we build a survey (S) with 16 questions that cover different aspects of hardware, software discovered by the user involved into this laboratory experiment regarding personal opinions. The values obtained from the survey were totalized for every mobile package and checked for reliability, or internal consistency, with Cronbach's Alpha test. The same procedure was fulfilled by the researcher Ahmed [8] who showed that his Cronbach's Alpha factor was greater than the threshold value of 0.60 that is an argument for the convergent validities of considered factors. The method used for Cronbach's Alpha test is shown by formula 6 .

$$
\alpha=\frac{K}{K-1}\left(1-\frac{\sum_{i=1}^{K} \sigma_{Y_{i}}^{2}}{\sigma_{X}^{2}}\right)
$$

where:

$\mathrm{K}=$ number of items

$\sigma_{X}^{2}=$ variance of the total test scores

$\sigma_{Y_{i}}^{2}=$ variance of the component $i$ for the current sample

The survey (S) contains 16 questions that offer the possibility to build a system of indicators used to answer to our questions research. These indicators were centralized into table 2, as is presented below, using two partitions for mobile device and educational criteria.

For every indicator we proceed to count the answers distributed to every mobile package developed. Every indicator was treated like an independent variable to apply a multiple correlation with the dependent variable, PE, represented by the indicator of the academic performance. 
Table 2. The system of quality indicators inserted into final survey questionnaire (S)

\begin{tabular}{|c|c|}
\hline Explanation for mobile device indicator & Explanation for educational indicator \\
\hline Type of mobile network & $\begin{array}{c}\text { Preexistent knowledge about } \\
\text { educational subject }\end{array}$ \\
\hline Type of operating mobile system & Utility of animation \\
\hline Display size & $\begin{array}{l}\text { Logical presentation of the educational } \\
\text { content }\end{array}$ \\
\hline $\begin{array}{l}\text { The temperature of mobile device during } \\
\text { application }\end{array}$ & $\begin{array}{c}\text { Correlation between learning } \\
\text { objectives and evaluation questionnaire }\end{array}$ \\
\hline Discharging mobile's battery & Virtual instructor evaluation \\
\hline Gaps over the video sequence & Sequentially operating mode \\
\hline Device calibration of font size & The importance of audio content \\
\hline \multicolumn{2}{|l|}{ Device landscape or portrait view } \\
\hline Speed browsing necessity & \\
\hline
\end{tabular}

\section{The proposed solution}

For our research we develop a strategy to gauge automatically the time allocated to every phase of our laboratory experiment with multimedia mobile applications developed. Every mobile application $\mathrm{APP}_{\mathrm{i}}$ deployed was equipped with internal capabilities to acquire the user name for the entire process depicted in figure 5. The activity SR1 and SR2 was inserted to emulate a dialog between a virtual instructor and the teachable person to recap something that was previous already explained. This activity, to recap in classroom, is usually done by every teacher to maintain the attention of the learners, to offer a pause in delivering new information and to remember together few important concepts.

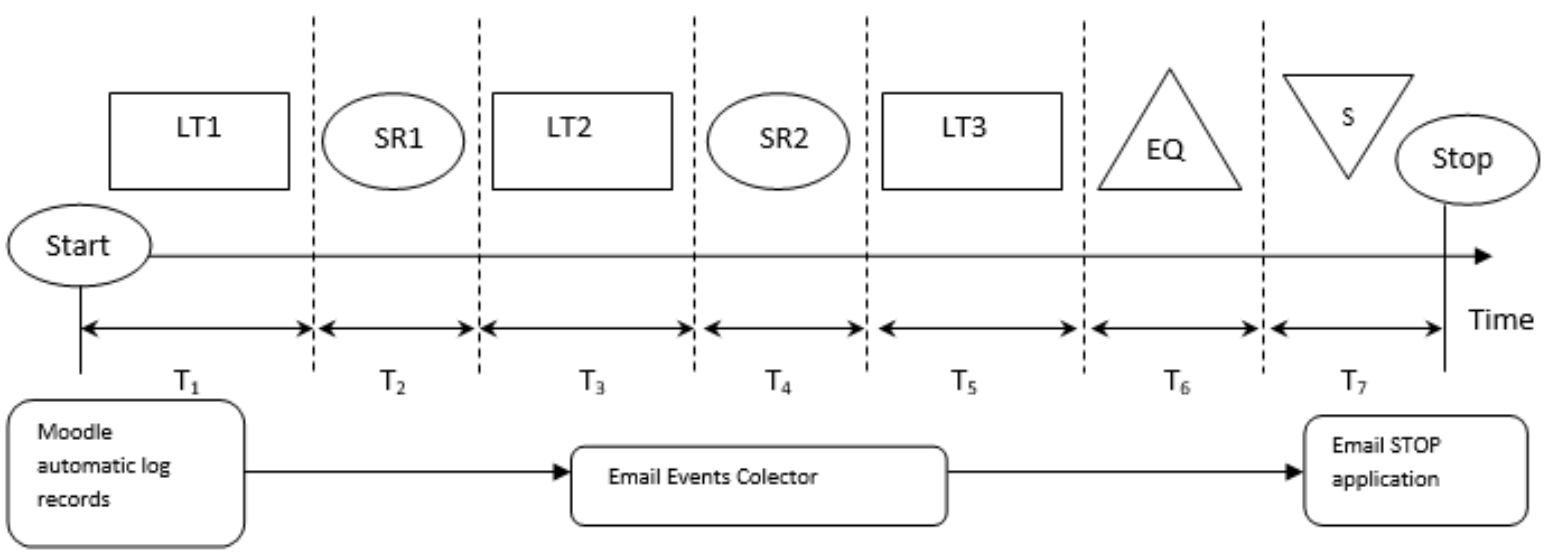

Fig. 5. The time coverage of every mobile application package APP(i)

where:

$\mathrm{T}_{1}=$ time for learning activity, LT1, in seconds
$\mathrm{T}_{3}=$ time for learning activity, LT2, in seconds

$\mathrm{T}_{5}=$ time for learning activity, LT3, in seconds 
$\mathrm{T}_{2}=$ time for recap simulation, $\mathrm{SR} 1$, in seconds

$\mathrm{T}_{4}=$ time for simulation, $\mathrm{SR} 2$, in seconds

$\mathrm{T}_{6}=$ time for evaluation questionnaire, $\mathrm{EQ}$, in seconds

$\mathrm{T}_{7}=$ time for survey, $\mathrm{S}$, in seconds

The phase EQ has a different transfer process by email for results obtained during a questionnaire to evaluate the level of educational acquisition. The phase $S$ represents the final stage that completes gauging the time consumed during the mobile application package. In figure 5 we depicted the framework of collecting data about time consumed with every phase. Every email received as we represent in figure 5 was send automatically to a unique collector email with detailed information about the action executed. The starting point, named Start in figure 5, was represented by a row inserted automatically into a $\log$ file, with the help of the Moodle website, generated by the login activity launch through a user intervention.

\section{Results}

The table 3 offers a centralized view of results obtained to discover correlation required by the first question of our research.

Table 3. The total time in seconds calculated for every phase, from column 2 to 7

\begin{tabular}{|c|c|c|c|c|c|c|c|c|c|}
\hline Order & LT1 & SR1 & LT2 & SR2 & LT3 & $\mathbf{E Q + S}$ & PE & $\operatorname{Avg}\left(\mathbf{R}_{\mathbf{e}}\right)$ & $\mathbf{A v g}\left(\mathbf{F}_{\mathbf{e}}+\mathbf{I}_{\mathbf{e}}\right)$ \\
\hline$(1)$ & $(2)$ & $(3)$ & $(4)$ & $(5)$ & $(6)$ & $(7)$ & $(8)$ & $(9)$ & $(10)$ \\
\hline APP1 & 3695 & 1773 & 4328 & 1190 & 13924 & 7637 & 1298 & 5,30 & 5,94 \\
\hline APP2 & 6738 & 1920 & 7368 & 1733 & 21372 & 10953 & 2088 & 6,24 & 6,67 \\
\hline APP3 & $\mathbf{1 0 4 3 9}$ & $\mathbf{1 5 5 9}$ & $\mathbf{8 7 3 2}$ & $\mathbf{1 3 3 3}$ & $\mathbf{3 1 8 3 3}$ & $\mathbf{1 7 3 6 9}$ & $\mathbf{2 8 8 5}$ & $\mathbf{6 , 7 0}$ & $\mathbf{6 , 9 1}$ \\
\hline APP4 & 4998 & 3313 & 5963 & 708 & 15230 & 13915 & 1492 & 6,06 & 6,10 \\
\hline
\end{tabular}

We search with multiple correlation regression the nature of interconnection between independent variable represented by LT1, SR1, LT2, SR2, LT3 and the dependent variable represented by arithmetic average of the evaluation resultant force of evaluation. Table 3 contains the indicator personal evaluation of academic performance, shown in column 8 , for the same multimedia mobile applications studied to a deepened reasoning concerning values versus arithmetic average of the resultant force of evaluation, shown in column 9. To solve multiple correlation regression and simple correlation regression we used option regression from add-ins Analysis ToolPak from the application named
Excel. In table 4 we are illustrating that between dependent variable, Y represented by the variable $R_{\mathrm{e}}$ from column 9 shown in table 3 , and the independent variables represented by the phases SR1 and SR2, reveal a weak correlation that could not explained the scores obtained, related to arithmetic average of the resultant force of evaluation, at every mobile application package studied, from APP1 to APP4. The same situation, shown in table 5, occurs when we studied the correlation between dependent variable $Y$, represented by the indicator $\mathrm{PE}$ as self-evaluation of academic performance, and the independent variables represented by the phases SR1 and SR2.

Table 4. The parameters for multiple-single correlation statistics between SR1 / SR2 and Re.

\begin{tabular}{|c|c|c|l|l|l|}
\hline Multiple R & R Square & Significance F & SR1 & SR2 & Intercept \\
\hline 0.290504379 & 0.084393 & 0.956874 & 0.000164 & 0.000582 & 5.005283 \\
\hline 0.097754282 & 0.009556 & 0.902246 & $-7.2 \mathrm{E}-05$ & & 6.231929 \\
\hline 0.251857689 & 0.063432 & 0.748142 & & 0.000347 & 5.646999 \\
\hline
\end{tabular}


Table 5. The parameters for multiple-single correlation statistics between SR1 / SR2 and PE.

\begin{tabular}{|c|l|c|l|l|l|}
\hline Multiple R & R Square & Significance $F$ & SR1 & SR2 & Intercept \\
\hline 0.529023635 & 0.279866007 & 0.84860709 & -0.319243522 & 0.3463105 & 2194.559 \\
\hline 0.511975889 & 0.262119311 & 0.488024111 & -0.459512428 & & 2924.681 \\
\hline 0.476051073 & 0.226624624 & 0.523948927 & & 0.80280631 & 944.4674 \\
\hline
\end{tabular}

In table 6 we represent that between learning time from every phase as independent variables and the dependent variable exposed by arithmetic average of the resultant force of evaluation, $R_{e}$, may be a strong correlation in every model of combining those phases allocated to the learning process.

Table 6. The parameters for multiple-single correlation statistics: LT1, LT2, LT3, EQ+S and

\begin{tabular}{|r|l|r|l|l|l|l|r|}
\hline Multiple R & R Square & \multicolumn{1}{|c|}{ Significance F } & LT1 & LT2 & LT3 & EQ+S & Intercept \\
\hline 0.94225 & 0.887837714 & 0.334906384 & & & $3.099 \mathrm{E}-05$ & $7.96 \mathrm{E}-05$ & 4.4465 \\
\hline 0.9850 & 0.970394428 & 0.172062698 & & 0.000393343 & $-2.256 \mathrm{E}-05$ & & 3.9475 \\
\hline 0.98077 & 0.961910279 & 0.19516588 & $-4.824 \mathrm{E}-05$ & 0.000374142 & & & 3.9217 \\
\hline
\end{tabular}

The same situation, shown in table 7, occurs when we studied the correlation between dependent variable $\mathrm{Y}$, represented by the indicator PE as self-evaluation of academic performance, and the independent variables represented by the phases LT1, LT2, LT3 and $\mathrm{EQ}+\mathrm{S}$.

Table 7. The parameters for multiple -single correlation statistics: LT1, LT2, LT3, EQ+S and PE

\begin{tabular}{|l|l|l|l|l|l|l|l|}
\hline Multiple R & R Square & $\begin{array}{c}\text { Significance } \\
\boldsymbol{F}\end{array}$ & LT1 & LT2 & LT3 & EQ+S & Intercept \\
\hline 0.996196815 & 0.992408094 & 0.087131545 & & & 0.086272388 & 0.001927755 & 140.3869 \\
\hline 0.999460017 & 0.998920325 & 0.032858414 & & 0.08431997 & 0.068859896 & & -33.3801 \\
\hline 0.994678104 & 0.989384531 & 0.103031397 & 0.232669716 & 0.01593904 & & & 330.7968 \\
\hline
\end{tabular}

In figure 6 we are representing the occurrence of the phenomenon studied like overestimation, underestimation and equal estimation using 116 valid responses from our population tested. For the system of indicators, that refer to the survey questionnaire, shown in table 2 , we obtain a value of 0.945814 for Cronbach's Alpha test, with the formula 2 previously explained, which is much greater than the threshold value of 0.60 . In this case we consider the model reliable to proceed for an investigation concerning multiple regression correlation between those independent indicators, $X_{i}$, and the dependent variable, $\mathrm{Y}_{\mathrm{i}}$, represented by the variable PE. 


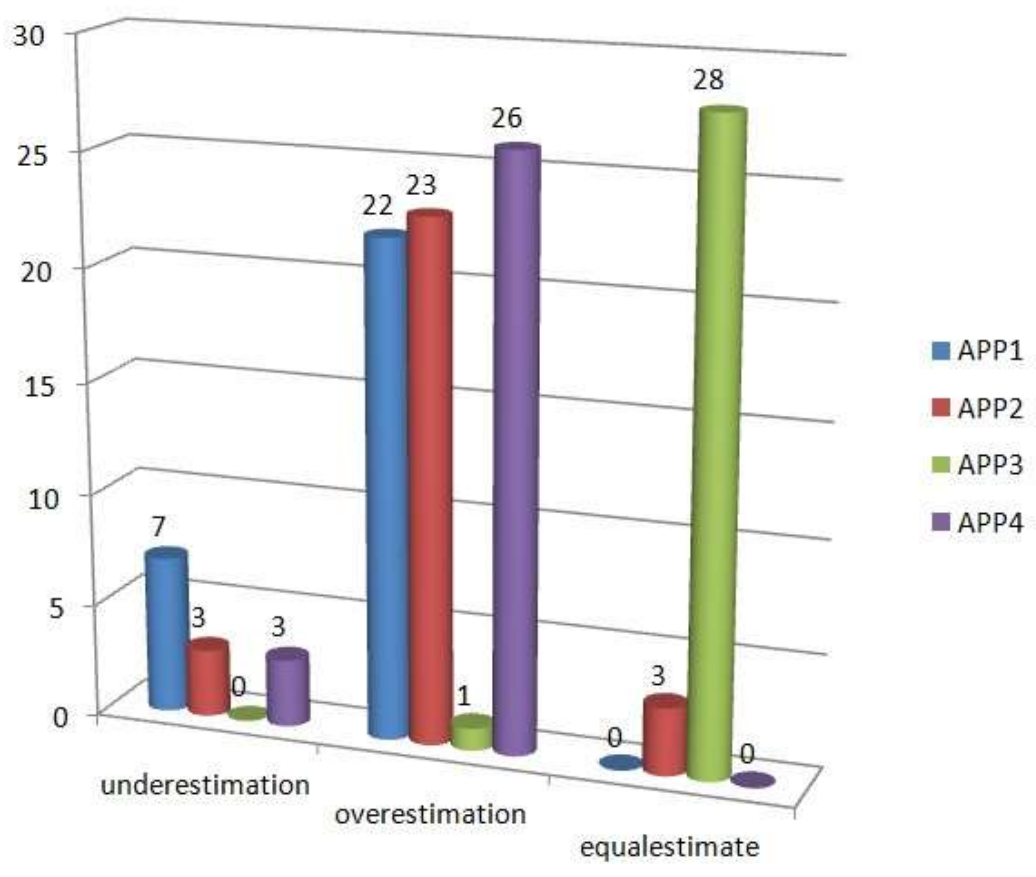

Fig. 6. The characteristics of self-efficacy about informal evaluation of academic performance

In table 8 we selected only relevant values correlation -between variables represented as calculated with Analysis ToolPak - indicators inserted in survey questionnaire.

Table 8. The relevant correlation between $\mathrm{PE}$ and the indicators of quality regarding mobile applications

\begin{tabular}{|l|c|l|}
\hline \multicolumn{1}{|c|}{ Indicator } & Correlation & \multicolumn{1}{c|}{ User's option } \\
\hline $\begin{array}{l}\text { Preexistent knowledge about } \\
\text { educational subject }\left(\mathrm{Ind}_{1}\right)\end{array}$ & 0.983368 & $\begin{array}{l}\text { No previous knowledge about the educational } \\
\text { subject experimented }\end{array}$ \\
\hline Type of operating mobile system $\left(\mathrm{Ind}_{2}\right)$ & 0.909884 & iOS \\
\hline Speed browsing necessity $\left(\mathrm{Ind}_{3}\right)$ & 0.939247 & YES speed OK for next page \\
\hline
\end{tabular}

Table 9. The significant multiple correlations between PE and the indicators of quality regarding mobile applications studied

\begin{tabular}{|c|c|c|c|c|c|c|}
\hline Multiple R & R Square & Significance $\boldsymbol{F}$ & Ind & Ind $_{2}$ & Ind 3 & Intercept \\
\hline 0.999712162 & 0.999424407 & 0.023991522 & 54.02453 & 29.60757 & & 252.2451 \\
\hline 0.939720356 & 0.883074348 & 0.341943931 & & 9.985517 & 64.83874 & 360.8208 \\
\hline 0.994244552 & 0.98852223 & 0.107134357 & 52.41219 & & 24.49104 & 47.0681 \\
\hline
\end{tabular}

In table 8, the column named - User's option - represents the choice selected by the user when he solves the survey questionnaire. When we applied multiple regressions correlation we find only that three indicators have a significant connection that explains the values recorded for personal self-academic performance. In table 9 we represent those indicators that have a significant multiple correlation with PE, personal self-evaluation of academic performance.

\section{Discussions and conclusions}

We discovered that both indicator of selfefficacy regarding personal evaluation of academic performance, $\mathrm{PE}$, and the resultant of force evaluation $R_{e}$, are evolving in a similar pattern. The final classification in a 
descending order, accordingly with PE and $\mathrm{R}_{\mathrm{e}}$, shows the multimedia mobile application arrangement: APP3, APP2, APP4 and APP1. From table 3 we found that APP1 and APP4 produced lowest values both for the arithmetic average of the resultant of evaluation force and for the indicator PE. The same classification occurs when we compare the values between the indicator metric of selfevaluation PE with the arithmetic average of the resultant of evaluation force. The maximum value occurs at the level of the APP3. A low value of PE and for the resultant of force evaluation is meaning that the users have a weak recognition of what they are able to learn or not and, accordingly, they neglect to transmit a correct self-evaluation of their academic performance. A high value of $\mathrm{PE}$ and for the resultant of force evaluation is meaning that the users have a good recognition of what they are capable to learn and understand due to the fact that the difference between formal evaluation, FE, and informal evaluation, IE which is meaning selfevaluation, is very low. As a consequence of a high value of $\mathrm{PE}$ is the fact that the phenomenon of equal estimation is preponderant as we depicted in figure 6 . The lowest value of indicator PE and for the resultant of force evaluation was obtained for mobile application APP1 with the maximum content of multimedia components. In this case the impact of the multimedia application, represented by the value of $P E$ and $R_{e}$, has a minimum and negative influence toward their capacity to create a correct image about selfefficacy of informal academic performance evaluation. The multiple regression correlation between time learning, represented by LT1-LT2-LT3 table 7, and the values of $\mathrm{PE}$ against the same action involving dialog simulation for recap with a virtual instructor, represented by the SR1-SR2 table 5 , shows that the students are willing to have a proneness for a quick learning memorize action to the detriment of a steady assimilation of new knowledge by doing a recap simulation. The similar comparative action between LT1-LT2-LT3 table 6 representing multiple regression correlation between time learning and $\mathrm{R}_{\mathrm{e}}$ reveals a strong correlation that indicates the fact that the students have the tendency to desire or to study with areas with high learning energy, exothermic activities deployed by a teacher where a teachable person has a passive role, instead of consuming events with low energy levels represented by the values from table 4 with areas of SR1 and SR2, known in our experiment as recap or homework zone. The multiple correlation between quality indicators, embedded into survey questionnaire, reveals that the dependent variable $\mathrm{PE}$ could be explained by a mix of factors consisting of the fact that they do not have previous knowledge about the educational subject experimented with APP1APP4, they used mobile devices with iOS and they considered a good browsing action from one phase to another during the usage of the mobile application experimented - table 8 . The maximum value for PE - table 3 - was encountered to APP3, where the value of multimedia percent support is $28 \%$ that produce an acceptable level of recognition involving self-efficacy of academic performance. The final conclusion is that the impact of multimedia mobile application on educational process is simultaneously maximized at a medium percent of multimedia components with areas where high energy occurs and that phenomenon could be explained by a low level of possibilities to distract the attention or to generate irregular addiction like social sites and, last but not least, by the application's area where the teachable person encounters exothermic events not endothermic ones. We propose to name by exothermic events those actions allocated to the teacher when the teachable person has a passive attitude during classroom activities and by endothermic events those actions when the teachable person has an active attitude like when he solves a problem or give an answer related to a question pose by the teacher. In this case the mobile application with multimedia support could be the guidance needed for a teachable person that prefers to learn with a mobile solution. The consequence of our study is very 
important, on educational process, because for a teacher is much easier to work with a group of learners that have a good awareness of what they learn and understand, with a high level of metric named PE and a tendency to desire exothermic events. More rational learning is meaning a better self-evaluation of academic performance and a high value of PE but in a careful way regarding a well-balanced division between exothermic and endothermic educational actions. An indicator metric of self-evaluation academic performance should be a formal standard toward any educational field anywhere and anytime. Studying consumption of energy required from teachable persons implies a more quantitative and qualitative efforts to understand deep connections regarding educational process with multimedia mobile applications.

The following actions will be considered to more quantitative and qualitative explorations of this subject:

- Studying a new approach for developing mobile application that covers more hardware functions of the mobile devices.

- Considering a new model to emulate time coverage and learner's energy consumption at the interface between learning and evaluation or an accurate remembering of previous knowledge acquired.

\section{Acknowledgment}

Parts of this research have been published in the Proceedings of the 19th International Conference on Informatics in Economy, IE 2020 [22]

\section{References}

[1] J. Mendoza, B. Pody, S. Lee and M. Kim, "The Effect of Cellphones on Attention and Learning: The Influences of Time, Distraction, and Nomophobia," Computers in Human Behavior, Vol. 86, 2018.

[2] S. Gokçearslan, K. Mumcu and T. Hasslaman, "Modelling Smartphone Addiction: The Role of Smartphone Usage, Selfregulation, General SelfEfficacy and Cyberloafing in University
Students," Computers in Human Behavior, Vol. 63, Pp. 639 - 649, 2016.

[3] A. Bakon and Z. Hassan, "Perceived Value of Smartphone and Its Impact on Deviant Behaviour: An Investigation on Higher Education Students in Malaysia," International Journal of Information System and Engineering (IJISE), Vol. 1, No. 1, 2013.

[4] S. Shahibi, "The Effect Of Smartphone That Influence The Compulsive Usage Among Students," International Journal Of Academic Research In Business And Social Sciences, Vol. 7, No. 8, 2017.

[5] M. D. Salvation, "The Relationship between Smartphone Applications Usage and Students' Academic Performance," Computational Methods in Social Sciences, Vol. 5, No. 2, Pp. 26-39, 2017.

[6] S. Amez And B. Stijn, "Smartphone Use And Academic Performance: A Literature Review," IZA - Institute Of Labor Economics, No. 12723, 2019 Oct..

[7] A. A. Khan, "Revealing the Relationship between Smartphone Addiction and Academic Performance of Students: Evidences from Higher Educational Institutes of Pakistan," Pakistan Administrative Review, Vol. 3, No. 2, 2019.

[8] R. R. Ahmed, "Smartphone Use and Academic Performance of University Students: A Mediation and Moderation Analysis," Sustainability, P. 439, 2020.

[9] S. N. Foen, "The Relationship between Smartphone Use and Academic Performance A Case of Students in A Malaysian Tertiary Institution," Malaysian Online Journal Of Educational Technology, Vol. 5, Pp. 58-70, 2017.

[10] H. Winskel, "Smartphone Use and Study Behavior: A Korean and Australian Comparison," Heliyon, Vol. 5, No. 7, 2019 July.

[11] K. Sumathi, S. Lakshmi And S. Kundhavai, "Reviewing The Impact Of Smartphone Usage On Academic Performance Among Students Of Higher Learning," International Journal Of Pure 
And Applied Mathematics, Vol. 118, No. 8, 2018.

[12] F. Giunchiglia and M. Zeni, "Mobile Social Media Usage and Academic Performance," Computers in Human Behavior, 2018.

[13] L. Kibona and G. Mgaya, "Smartphones' Effects on Academic Performance of Higher Learning Students," Journal of Multidisciplinary Engineering Science and Technology (JMEST), Vol. 2, No. 4, 2015.

[14] E. Chukwuere, "The Financial And Academic Implications Of Using Smartphones Among Students: A Quantitative Study," Journal Of Economics And Economic Education Research, Vol. 18, No. 1, 2017.

[15] H. Sunyoung, "How Does the Smartphone Usage of College Students Affect Performance," J Comput Assist Learn, Vol. 35, Pp. 13-22, 2019.

[16] G. Jesse, "Smartphone and App Usage among College Students: Using Smartphones Effectively for Social and Educational Needs," Issues in Information Systems, no. IV, pp. 8-20, 2016.

[17] M. Alfawareh, "The Use and Effects of Smartphones in Higher Education," iJIM, vol. 11, no. 6, 2017.
[18] O. Boahene, J. Fang and F. Sampong, Sustainability, vol. 11, p. 2431, 2019.

[19] C. Wei, F. He and S. Huang, "Effects of Instructional Multimedia Integrated Situational Approach on Students' Learning Achievement," EURASIA Journal of Mathematics, Science and Technology Education, vol. 14, no. 7, pp. 3321-3327, 2018.

[20] A. Hossain, M. Nurunnabi and K. Hussain, "Effects of variety-seeking intention by mobile phone usage on university students' academic performance," Cogent Education, vol. 6, 2019.

[21] J. Wang and T. Mendori, "Strategies for Multimedia Learning Object Recommendation in a Language Learning Support System: Verbal Learners vs. Visual Learners," International Journal of Human-Computer Interaction, vol. 35, p. 345-355, 2019.

[22] D. Mihail-Văduva, "The impact of a multimedia mobile application," in Proceedings of the IE 2020 International Conference, București, 2020.

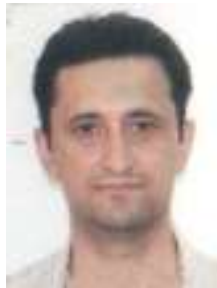

Dinu MIHAIL-VĂDUVA has graduated the Faculty of Economic Cybernetics, Statistics and Informatics of the Bucharest Academy of Economic Studies in 2010. He received an alumnus achievement award in 2012 of the Informatics Economics Master affiliated to the Bucharest University of Economic Studies. Starting with 2017 he was admitted to the PhD student at the Doctoral School of The Bucharest University of Economic Studies, Economic Informatics domain for his $\mathrm{PhD}$ thesis proposal involving educational systems based on mobile technologies. Between 2016 and 2017 he finished with a high school diploma postgraduate training programs named Psychological, Pedagogical and Educational skills training, level I and II, connected with a particular branch of the Bucharest University of Economic Studies. Furthermore, he graduated classes between 1984 and 1989 with a bachelor degree of the Faculty of Technology for Chemistry of the Polytechnic Institute of Bucharest towards specialization concerning Inorganic Chemistry Engineering. Currently he is working as a software analyst within the Department of Information Technology at the Regia Autonomă "Monitorul Oficial" from Bucharest and he is using Oracle database with APEX technology correlated with specific software languages for intranet projects development. His main scientific preoccupation is heavily orientated towards domains situated at the interface between education as a primarily economic and social activity and the most recent software technology. 